\title{
Article \\ Perceived Efficiency Outcomes, Sources and Awareness of Online Health Information among the Elderly during COVID-19
}

\author{
Gizell Green ${ }^{1, *} \mathbb{B}$, Riki Tesler $^{2}$ and Cochava Sharon ${ }^{1}$ \\ 1 Nursing Department, School of Health Sciences, Ariel University, Ariel 40700, Israel; cochishar@gmail.com \\ 2 Department of Health Systems Management, School of Health Sciences, Ariel University, Ariel 40700, Israel; \\ rikite@ariel.ac.il \\ * Correspondence: ggrin@alumni.technion.ac.il
}

Citation: Green, G.; Tesler, R.;

Sharon, C. Perceived Efficiency

Outcomes, Sources and Awareness of

Online Health Information among the

Elderly during COVID-19. Int. J.

Environ. Res. Public Health 2021, 18

8121. https://doi.org/10.3390/

ijerph18158121

Academic Editor: Paul B. Tchounwou

Received: 24 June 2021

Accepted: 27 July 2021

Published: 31 July 2021

Publisher's Note: MDPI stays neutral with regard to jurisdictional claims in published maps and institutional affiliations.

Copyright: (c) 2021 by the authors Licensee MDPI, Basel, Switzerland. This article is an open access article distributed under the terms and conditions of the Creative Commons Attribution (CC BY) license (https:// creativecommons.org/licenses/by/ $4.0 /)$

\begin{abstract}
The Internet and social media are crucial platforms for health information. Factors such as the efficiency of online health information, the outcomes of seeking online health information and the awareness of reliable sources have become increasingly important for the elderly during the COVID-19 pandemic. This study aimed to examine differences between elderly individuals' income above and below the average monthly wage in relation to their online health information efficiency and the outcomes of seeking online health information; to evaluate types of online information sources with online health information efficiency and the outcomes of seeking online health information; and to explore online health information efficiency as a mediator between health status and awareness of online sources. A cross-sectional study design was conducted with 336 elderly participants age 65 or older. The participants volunteered to complete a questionnaire. No differences were found between the two groups regarding efficiency in retrieving health information from official online health sites and Google. Perceived efficiency mediated health status and awareness of online sources. In these challenging times, it is important to provide a tailor-made education strategy plan for reliable sources of online health information for the elderly, in order to enhance their technology safety skills. It is also important to explore other mediating variables between health status and awareness of online sources.
\end{abstract}

Keywords: online health information; elderly; COVID-19; perceived efficiency; awareness of online sources

\section{Introduction}

The Internet and social media platforms are crucial venues for health information [1,2] which in this study refers to all aspects of personal health, including physical and mental health handled in either physical or digital form [3]. The Internet and social media have become common channels for people to search for information about health, nutrition and everyday life $[2,4,5]$. eHealth literacy is the ability of individuals to use information and communication technologies such as the Internet to enhance health care [6].

Researchers have found that eHealth literacy is related to improved subjective health status [7-9], quality of life [10,11] and low risk of chronic illness [6]. eHealth literacy has been found to be a benefit factor for individuals aged 50-60 years [12]. In a study that developed an eHealth literacy scale, it was found that the awareness of different online health sources and perceived online health efficiency dimensions of the scale were the most developed dimensions, as users scored significantly higher in these two dimensions as compared to the others [13]. Therefore, in the current study, we focused on these two dimensions. Furthermore, online health information, which in this study refers to all aspects of health including physical and mental health handled in online form [3], can relate to other factors, such as the individual's income. Individuals with lower education and 
income levels, as well as those who are in poor health, have a higher risk of misinterpreting health information [14]. It is important to note that different sources of health information on the Internet are becoming ever more diverse and these different sources can impact healthcare decision making. Furthermore, little is known about the reasons influencing people's choice of online health sources [11].

The Internet offers sources of online health information, but the reliability of the data is often questionable. Uncertainties regarding the quality of online health information might have a harmful influence on individuals' health-related decisions [15]. Individuals with high education levels and incomes tend to find health information on hospital websites, which are considered a reliable source [16]. Additional research demonstrated concerns related to social media (which may be considered an unreliable source) when used as a health information source [17]. Another source that is very common for seeking online health information is the Google search engine (which may also be considered an unreliable source). Occasionally, Google's quality of online health data can be untrustworthy. It is known that the quality of online health data may have a harmful effect on individuals' health-related decisions [15]. Therefore, it is important to investigate the relationship between different sources of online health information according to their reliability measure, the perceived efficiency and the perceived outcomes.

Moreover, the lack of awareness of online sources can create avoiding behavior and is one of the reasons for not using devices to access digital health [18]. It is becoming more complicated for the elderly to be able to access reliable health information. The Internet's advantage can be used in a smart and careful way, especially during the COVID19 pandemic, in order to enhance patients' health status.

Although internet use among the elderly (age 65 or older) is growing, this population remains helpless due to the continuously increasing technological strains [19]. A study among elderly women participants who were recently diagnosed with breast cancer found that about half were categorized as having limited eHealth literacy [20]. Another study found that older men (age 65 or older) who were non-native English speakers (the dominant language on the Internet) had low levels of eHealth literacy [21]. These concerns are emphasized because of the global COVID-19 pandemic.

A worldwide pandemic broke out in 2019, called COVID-19 [22,23]. The COVID-19 pandemic has affected the quality of life of people worldwide. Physical isolation has been advised, which has strongly affected people's lives [24], particularly those in at-risk groups, such as individuals 65 years of age and older. With the new restrictions imposed globally, the Internet has become the main venue for all aspects of life and health. Some of the main resources that the Internet provides are knowledge and health services for patients. Therefore, factors such as the perceived efficiency of online health information (referring to the effectiveness in the search for and use of online health information [13]), the outcomes of seeking online health information and the awareness of reliable sources (referring to the recognition of trustworthy online health resources [13]) have become more important than ever $[7-10,25,26]$.

\section{Research Aims}

This study has three aims: first, to examine differences between elderly individuals who earn above average monthly wage and those who earn below average monthly wage in relation to their online health information efficiency and the outcomes of seeking online health information during the COVID-19 pandemic; second, to evaluate types of online information sources used by the elderly, their perception of online health information efficiency and the outcomes of seeking health information during the COVID-19 pandemic; and third, to explore a model of online health information efficiency as a mediator between health status and awareness of online sources during the COVID-19 pandemic. 


\section{Materials and Methods}

\subsection{Study Design}

A cross-sectional study design with a convenience sample was performed and reported according to the EQUATOR and STROBE checklists for cross-sectional studies [27]. The data were collected from May 2020 to August 2020.

\subsection{Participants and Procedure}

The study participants consisted of 336 elderly people aged 65 or older throughout Israel. We chose this population for three reasons: First, people over 65 years of age face more health challenges, making them a more vulnerable group. Second, the channels to obtain health information have been reduced and the main channel is online due to social distancing recommended during the COVID-19 pandemic. Third, due to information technology developments, it might difficult for the elderly to identify reliable online health information [21,22]. As of the beginning of May 2020, the number of total COVID-19 cases (people who were infected with the virus) in Israel was 16,101 with 2225 deaths (Worldometer, 2021) [28]. Participants were enrolled and data were collected through iPanel (https://www.ipanel.co.il/en/ (accessed on 31 May 2021)), which is an online sampling service that allows for fast responses, striving for a representative sample based on the population's sociodemographic characteristics, such as gender, age and health status. This panel is the largest panel survey in Israel and holds high quality research codes from the European Society for Opinion and Marketing Research (ESOMAR) [29,30].

An introductory e-mail was sent to potential participants via the iPanel database system. The e-mail directed participants to read the research objectives in detail as well as their rights, such as the right to withdraw at any time from the research, and included the contact details of the researchers. Then, they had the option to electronically sign informed consent to participate in the research and complete the questionnaire if they were interested, which took $10 \mathrm{~min}$ to complete. The survey directions emphasized its anonymity and confidentiality. The e-mail was sent to 1597 potential candidates and 336 expressed interest and participated in the study. The response rate for study participation was $27 \%$, which was considered a good response rate.

\subsection{Measures}

To evaluate participants' perceived efficiency of online health information, awareness of online sources, perceived outcomes of seeking online health information and health status, the questionnaire was composed of four sections. The first section referred to sociodemographic and background characteristics, which gathered information on participants' age, health status and sources from which they derived their health information. A list of online sources from which to choose was provided to the participants, including sources considered as reliable (e.g., official hospital sites) and unreliable (e.g., social networks).

The second section referred to the perceived efficiency of the online health information and awareness of different types of online sources. There were two subcategories from the eHealth literacy scale: (A) The perceived efficiency of online health information. This subcategory contained 4 items, including the following statement: "I feel confident using information from the Internet to make successful health decisions." The internal consistency of this subcategory was 0.76 (Cronbach's alpha). (B) Awareness of online sources. This subcategory consisted of 3 items, including: "I know where to find helpful health resources on the Internet." The internal consistency was 0.85 (Cronbach's alpha). Answers were based on a 5-point Likert-like scale ranging from 1 ("completely disagree") to 5 ("completely agree") [13].

The third section referred to perceived outcomes of seeking online health information and consisted of 8 items, including: "I updated my knowledge regarding health innovations." The internal consistency of this subcategory was 0.91 (Cronbach's alpha). The scale used a 5-point Likert-like scale ranging from 1 ("completely disagree") to 5 ("completely agree") [31]. 
Numerous researchers fluent in English with specialty in eHealth literacy checked the reliability of the translation of the scale from English into Hebrew and vice versa.

\subsection{Data Analysis}

Statistical analysis was performed using two types of software. The first type was the Statistical Package for the Social Sciences (SPSS TM) version 21.0 (IBM, Chicago, IL, USA) and was performed as follows: Cronbach's alpha, descriptive statistics, t-tests and one-way ANOVA. The second type, the Process, was developed to examine the mediation model [32].

\subsection{Ethical Considerations}

The study protocol was approved by the Ethics Committee of the Ariel University, confirmation number: AU-HEA-GG-20200329-1. The University Institutional Review Board gave permission to conduct this research. Participants were voluntarily recruited and informed of the goals of the research. They also signed an informed consent form before answering the questionnaire. The volunteers were assured that they had the right to withdraw from the research at any time, that their answers would be kept confidential and that the questionnaires would be analyzed anonymously.

\section{Results}

The mean age of the participants was 68 years $(\mathrm{SD}=2.91)$. For frequency and percentage of background characteristics, see Table 1 .

Table 1. Background characteristics of the study population.

\begin{tabular}{|c|c|c|c|}
\hline \multirow{2}{*}{\multicolumn{2}{|c|}{ Background Characteristic }} & \multicolumn{2}{|c|}{$n=336$} \\
\hline & & \multirow{2}{*}{$\begin{array}{l}n \\
152\end{array}$} & \multirow{2}{*}{$\begin{array}{l}\% \\
45\end{array}$} \\
\hline & Male & & \\
\hline Gender & Female & 184 & 55 \\
\hline \multirow{4}{*}{ Status } & Single & 6 & 2 \\
\hline & Married & 256 & 76 \\
\hline & Divorced & 46 & 14 \\
\hline & Widowed & 28 & 8 \\
\hline \multirow{3}{*}{ Religious } & Jewish & 333 & 99 \\
\hline & Muslim & 3 & 1 \\
\hline & Secular & 226 & 67 \\
\hline \multirow{3}{*}{ Religiosity } & Traditional & 74 & 22 \\
\hline & Religious & 30 & 9 \\
\hline & Very religious & 5 & 2 \\
\hline \multirow{4}{*}{ Education } & High school & 74 & 22 \\
\hline & Diploma & 114 & 34 \\
\hline & Bachelor's degree & 100 & 30 \\
\hline & Master's degree & 48 & 15 \\
\hline \multirow{2}{*}{ Financial Status } & Above average & 179 & 53 \\
\hline & Below average & 149 & 44 \\
\hline
\end{tabular}

Abbreviations: SD, standard deviation.

Most of the participants were female, married, Jewish and had a high school education level and had income above average wage.

To examine the first research aim (differences between elderly individuals' income above compared to below average monthly wage regarding online health information efficiency and outcomes), we performed an independent t-test analysis (Table 2).

There were no differences between the two groups as to their online health information efficiency or perceived outcomes of seeking online health information. 
Table 2. Differences between elderly individuals' income above and below average monthly wage regarding online health information efficiency and outcomes.

\begin{tabular}{|c|c|c|c|c|c|c|}
\hline \multirow[b]{2}{*}{ Variable } & \multicolumn{2}{|c|}{$\begin{array}{l}\text { Elderly Individuals' Income above } \\
\text { the Average Monthly Wage } \\
(n=149)\end{array}$} & \multicolumn{2}{|c|}{$\begin{array}{l}\text { Elderly Individuals' Income below } \\
\text { the Average Monthly Wage } \\
(n=179)\end{array}$} & \multirow[t]{2}{*}{$\mathbf{t}$} & \multirow[t]{2}{*}{${ }^{*} p$} \\
\hline & Mean & SD & Mean & SD & & \\
\hline $\begin{array}{l}\text { Perceived efficiency of } \\
\text { online health information }\end{array}$ & 3.51 & 0.77 & 3.64 & 0.81 & 1.63 & 0.10 \\
\hline $\begin{array}{l}\text { Perceived outcomes of } \\
\text { seeking health information }\end{array}$ & 3.73 & 0.81 & 3.85 & 0.84 & 1.26 & 0.21 \\
\hline
\end{tabular}

Notes: ${ }^{*} p<0.05$; Abbreviations: SD, standard deviation.

The results of the examination of the second research aim (evaluating types of online information sources, the perception of online health information efficiency and their outcomes) are described in Table 3.

Table 3. Types of online sources used by the elderly, their perception of online health information efficiency and the outcomes of seeking online health information.

\begin{tabular}{|c|c|c|c|c|c|c|c|c|}
\hline \multirow{4}{*}{$\begin{array}{l}\text { Variables } \\
\text { Online health } \\
\text { information efficiency } \\
\text { Perceived outcomes of } \\
\text { seeking online health } \\
\text { information }\end{array}$} & \multicolumn{2}{|c|}{$\begin{array}{l}\text { Social Networks } \\
\text { (Unreliable) }\end{array}$} & \multicolumn{2}{|c|}{$\begin{array}{l}\text { Official Online Health Sites } \\
\text { (Reliable) } \\
(n=179)\end{array}$} & \multicolumn{2}{|c|}{$\begin{array}{l}\text { Google } \\
\text { (Unreliable) } \\
(n=149)\end{array}$} & \multirow[t]{2}{*}{$\mathbf{F}$} & \multirow[t]{2}{*}{${ }^{*} p$} \\
\hline & Mean & SD & Mean & $\mathrm{SD}$ & Mean & SD & & \\
\hline & 3.10 & 0.80 & 3.66 & 0.78 & 3.56 & 0.73 & 4.44 & 0.01 \\
\hline & 3.64 & 0.88 & 3.87 & 0.83 & 3.79 & 0.79 & 3.27 & 0.04 \\
\hline
\end{tabular}

Notes: ${ }^{*} p<0.05$; Abbreviations: SD, standard deviation.

When comparing the reliability of different online sources, health information from official health sites (such as hospitals) and Google were more efficient than those who retrieved health information from social networks $(p<0.01$ and $p<0.05$, respectively). However, there were no differences between the two groups regarding retrieved health information from official online health sites (such as hospital sites) and Google as to efficiency $(p>0.05)$. In addition, the group that retrieved health information from official online health websites perceived the outcomes of seeking online health information more positively than the group that retrieved health information from social networks $(p<0.05)$. However, there were no differences between the two groups regarding retrieved health information from official online health sites (such as hospital sites) and Google as to perceived outcomes of seeking online health.

In order to examine the relationship between research variables, we conducted a Pearson correlation analysis (Table 4).

Table 4. Pearson correlations between the variables.

\begin{tabular}{|c|c|c|c|c|}
\hline Variables & Health Status & $\begin{array}{l}\text { Awareness of Online } \\
\text { Sources }\end{array}$ & Perceived Efficiency & $\begin{array}{l}\text { Perceived Outcomes of } \\
\text { Seeking Online Health } \\
\text { Information }\end{array}$ \\
\hline Health status & 1 & 0.14 * & $0.19 * *$ & 0.09 \\
\hline Awareness of online sources & & 1 & $0.62 * *$ & $0.56^{* *}$ \\
\hline Perceived efficiency & & & 1 & $0.67^{* *}$ \\
\hline $\begin{array}{l}\text { Perceived outcomes of } \\
\text { seeking online health } \\
\text { information }\end{array}$ & & & & 1 \\
\hline
\end{tabular}


There were weak relationships between health status, awareness of online sources and perceived efficiency $(r=0.14, p<0.05 ; r=0.19, p<0.00)$, respectively. Significant medium up to strong relationships were found between awareness of online sources, perceived efficiency and perceived outcomes of seeking online health information $(\mathrm{r}=0.62, p<0.00$; $r=0.56, p<0.005)$, respectively. Moreover, relationships were found between perceived efficiency and perceived outcomes of seeking online health information $(\mathrm{r}=0.67, p<0.00)$.

In order to examine the third research aim (exploring a model of online health information efficiency as a mediator between health status and awareness of online sources), we conducted a series of regression analyses via PROCESS analysis [33] (Figure 1).

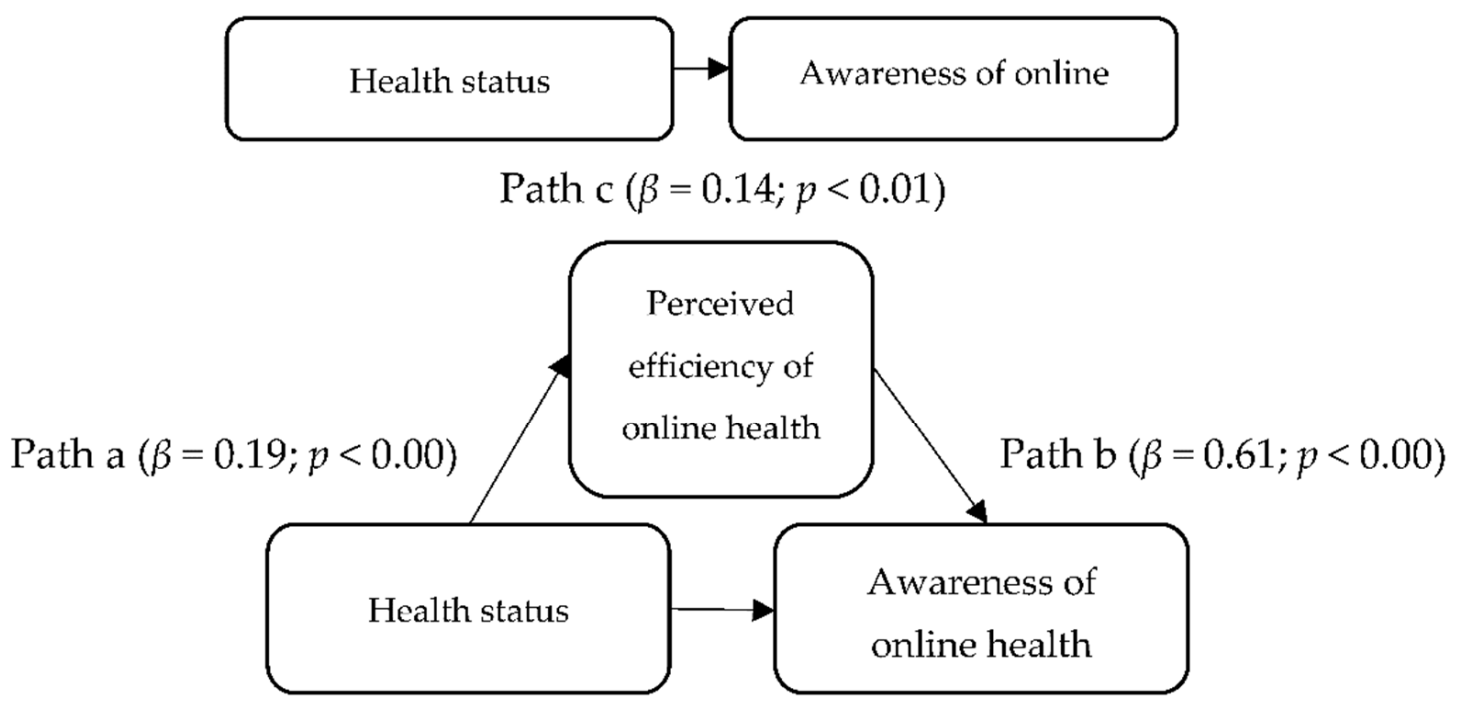

Path $c^{\prime}(\beta=0.03 ; p>0.05)$

Figure 1. Mediation model.

Figure 1 shows the relationship between health status, awareness of online sources and perceived efficiency, with perceived efficiency as the mediation variable. In step 1 , the regression of health status regarding awareness of online sources was significant $(\beta=0.14$, $p<0.00$ ). Step 2 shows that health status as perceived efficiency mediator was also significant $(\beta=0.19, p<0.00)$. Step 3 shows that regression of the mediator (perceived efficiency) with awareness of online sources controlling health status was also significant $(\beta=0.61$, $p<0.00$ ). Step 4 of the analysis revealed that when controlling for the mediator (perceived efficiency), health status was not a significant predictor of awareness of online sources ( $\beta=0.03, p=0.62$ ). In addition, health status had a positive indirect effect on awareness of online sources through perceived efficiency $(\beta=0.12, \mathrm{SE}=0.03,95 \% \mathrm{CI}[0.05,0.18])$. Accordingly, it was found that subjective perceived efficiency fully mediated the relationship between health status and awareness of online sources.

\section{Discussion}

The study strived to (a) examine differences between elderly individuals' income above and below the average monthly wage in relation to their online health information efficiency and the outcomes of seeking online health information during the COVID-19 pandemic period; (b) evaluate types of online information sources used by the elderly, their perception of online health information efficiency and the outcomes of seeking online health information; and (c) explore online health information efficiency as a mediator between health status and awareness of online sources.

First, no differences were found between the elderly population's income above and below the average monthly wage in relation to their online health information efficiency 
and the outcomes of seeking online health information. Surprisingly, the research literature demonstrated inconsistency in this respect. One study found that among the elderly with a low income, lower levels of internet usage were attributable to the absence of financial funds for purchasing technological assistance [33]. Moreover, the elderly with lower income were associated with the use of internet activities such as finding health information, cooperating with health care workers and assessing health [33-35]. A possible explanation for our surprising results is that seeking online health information is related to many reasons and is a combination of eHealth literacy, phone possession, technical ability, as well as social recognition of health requirements [18], highlighting the large-scale use of mobile phones to promote health, described as "online health lifestyle" [36]. Another possible explanation is that although the elderly appears to trust persons with whom they are able to actively discuss their health, as opposed to accessing an inanimate source as the Internet [37], the Internet has become a main and important technological channel for obtaining health information for this population while we are in the midst of a global pandemic with the requirement of social distancing and the accessibility of smart phones at convenient prices. Therefore, we conclude that in these challenging times, it is important for government and health care organizations to provide appropriate eLiteracy evaluation and to provide an education plan for the elderly so that they can enhance their technology and safety skills.

Second, we found that the groups that retrieved health information from official online health sites considered their efficiency to be higher than the group that retrieved health information from social networks. In addition, the group that retrieved health information from official online health sites perceived outcomes of seeking online health information more positively than the group that retrieved health information from social networks. Similarly, we found that hospital/institutional websites (considered as reliable sources) were the most popular internet sites used and it was of the essence that hospitals made critical information easy to find and understand [16].

One concern emerged from the results: the group that retrieved health information from Google considered its efficiency to be higher than the group that retrieved health information from social networks. Similar to our results, one study found that age was one of the factors that could explain differences in the capability of examining the value of information [7]. Another study found that younger participants were more confident in distinguishing reliable or unreliable facts of health-related internet information [19]. It is essential to know where to find reliable health online sources to develop electronic health abilities [7]. In this study, perhaps because Google has great popularity including among the elderly, it was mistakenly considered a reliable health information source. Therefore, examining accessibility of reliable online sources and tools of health information is important for the elderly [37].

Third, it was found that perceived efficiency fully mediated the relationship between health status and awareness of online sources. Health status has been extensively researched in many aspects of internet health information [11,38,39]. In addition, health status and internet use affect the frequency and amount of online health information that is sought [7,40]. After a broad review of contemporary research literature, we did not find research that performed in-depth analysis for detecting online health information efficiency as mediator between health status and awareness of online sources. The novelty in the present study is the finding that the health status of an elderly person predicts their awareness of sources of online health information only when perceived efficiency of this health information serves as a full mediator. When controlling the mediating variable, perceived efficiency, the relation between health status and awareness of sources for online health information is canceled. Our alternative explanation for this important finding is due to the recurring lockdowns and extensive recommendations for social distancing for the elderly population in COVID-19 times, causing health and medicine in all aspects to be consumed almost exclusively via the Internet and so the perceived efficiency of the Internet for health needs has become a very significant and influential mediator. 


\section{Conclusions}

First, no differences were found between elderly individuals' average monthly wage and their online health information efficiency and seeking online health information. These two groups perceive their online health information efficiency and seeking online health information equally. Therefore, the health care system needs to provide guidance in finding trustworthy online health information oriented to elderly populations since it has become accessible to everyone due to affordably priced technology devices with internet access.

Second, there were no differences found between the two groups regarding retrieved health information from official online health sites (such as hospital sites) and Google as to the efficiency of health information and perceived outcomes of seeking online health. Moreover, the group that retrieved health information from Google considered its efficiency to be higher than the group that retrieved health information from social networks. The elderly mistakenly consider Google to be a reliable source of online health information. The health care system needs, especially during the COVID-19 period, to provide a tailor-made education strategy plan for distinguishing between unreliable and reliable sources of online health information [2] for the elderly, in order to enhance their technology safety skills.

Third, perceived efficiency fully mediated the relationship between health status and awareness of online sources. We conclude that perceived efficiency has a crucial mediating role between these two variables in relation to the elderly. Therefore, in future research it is necessary to explore this model while adding other mediating variables in order to fully understand the relationship between those variables. Today, gaining deep understanding of online health information among the elderly is not a luxury, but a vital necessity, especially since they are increasingly dependent on the online health information.

\section{Limitations}

There are several limitations to this study. First, our findings are based on a selfreporting questionnaire and not an objective tool. More studies, measuring the actual use of online health information searches, are required.

Second, the cross-section study design with convenience sampling approach limits generalizability of the study results and the representativeness of the study sample. Therefore, it is required to evaluate online health information in a large sample and in different countries. The third limitation is the use of one tool (the questionnaire) in this study. Therefore, future studies should focus on and use various tools, such as observations or semi-structured interviews, which might be useful for detecting more complex and deeper insights and explanations for measuring online health information search behavior phenomena.

Author Contributions: Conceptualization, G.G.; methodology, G.G. and C.S.; validation, G.G. and R.T.; formal analysis, G.G.; writing — original draft preparation, G.G., C.S. and R.T.; writing—review and editing, G.G., C.S. and R.T.; visualization, G.G.; supervision, G.G.; project administration, R.T. All authors have read and agreed to the published version of the manuscript.

Funding: This research received no external funding.

Institutional Review Board Statement: This study was conducted according to university ethical guidelines and approved by the Institutional Review Board (IRB) of Ariel University.

Informed Consent Statement: Informed consent was obtained from all research participants involved in the study.

Acknowledgments: This research is the result of research conducted in the university.

Conflicts of Interest: The authors declare no conflict of interest. 


\section{References}

1. Alhuwail, D.; Abdulsalam, Y. Assessing Electronic Health Literacy in the State of Kuwait: Survey of Internet Users from an Arab State. J. Med. Internet Res. 2019, 21, e11174. [CrossRef] [PubMed]

2. Sturiale, A.; Pata, F.; De Simone, V.; Pellino, G.; Campennì, P.; Moggia, E.; Manigrasso, M.; Milone, M.; Rizzo, G.; Morganti, R.; et al. Internet and social media use among patients with colorectal diseases (ISMAEL): A nationwide survey. Color. Dis. 2020, 22, 1724-1733. [CrossRef] [PubMed]

3. Chernyshev, M.; Sherali, Z.; Zubair, B. Healthcare data breaches: Implications for digital forensic readiness. J. Med. Syst. 2019, 43, 7. [CrossRef] [PubMed]

4. Reid, P.; Borycki, E.M. Emergence of a new consumer health informatics framework: Introducing the healthcare organization. In ITCH; IOS Press: Amsterdam, The Netherlands, 2011; pp. 353-357.

5. Bidmon, S.; Terlutter, R. Gender Differences in Searching for Health Information on the Internet and the Virtual Patient-Physician Relationship in Germany: Exploratory Results on How Men and Women Differ and Why. J. Med. Internet Res. 2015, 17, e156. [CrossRef]

6. Neter, E.; Brainin, E. eHealth Literacy: Extending the Digital Divide to the Realm of Health Information. J. Med. Internet Res. 2012, 14, e19. [CrossRef]

7. Vicente, M.R.; Madden, G. Assessing eHealth skills across Europeans. Health Policy Technol. 2017, 6, 161-168. [CrossRef]

8. Hogan, T.P.; Hill, J.N.; Locatelli, S.M.; Weaver, F.M.; Thomas, F.P.; Nazi, K.M.; Goldstein, B.; Smith, B.M. Health Information Seeking and Technology Use among Veterans with Spinal Cord Injuries and Disorders. PM R 2016, 8, 123-130. [CrossRef]

9. Aponte, J.; Nokes, K.M. Electronic health literacy of older Hispanics with diabetes. Health Promot. Int. 2015, 32, 482-489. [CrossRef]

10. Hsu, W.; Chiang, C.; Yang, S. The Effect of Individual Factors on Health Behaviors Among College Students: The Mediating Effects of eHealth Literacy. J. Med. Internet Res. 2014, 16, e287. [CrossRef]

11. Zhang, Y.; Sun, Y.; Kim, Y. The influence of individual differences on consumer's selection of online sources for health information. Comput. Hum. Behav. 2017, 67, 303-312. [CrossRef]

12. Mitsuhashi, T. Effects of two-week e-learning on eHealth literacy: A randomized controlled trial of Japanese Internet users. PeerJ 2018, 6, e5251. [CrossRef]

13. Petrič, G.; Atanasova, S.; Kamin, T.; Coulson, N.; Amann, J.; Roland, D. Ill Literates or Illiterates? Investigating the eHealth Literacy of Users of Online Health Communities. J. Med. Internet Res. 2017, 19, e331. [CrossRef]

14. Liu, P.; Yeh, L.-L.; Wang, J.-Y.; Lee, S.-T. Relationship Between Levels of Digital Health Literacy Based on the Taiwan Digital Health Literacy Assessment and Accurate Assessment of Online Health Information: Cross-Sectional Questionnaire Study. J. Med. Internet Res. 2020, 22, e19767. [CrossRef]

15. Battineni, G.; Baldoni, S.; Chintalapudi, N.; Sagaro, G.G.; Pallotta, G.; Nittari, G.; Amenta, F. Factors affecting the quality and reliability of online health information. Digit. Health 2020, 6, 1-11. [CrossRef] [PubMed]

16. Lussiez, A.D.; Burdick, S.; Kodali, S.; Rubio, G.; Mack, J.A.; Lin, J.; Chang, A.C.; Reddy, R.M. Internet Usage Trends in Thoracic Surgery Patients and Their Caregivers. J. Cancer Educ. 2015, 32, 91-96. [CrossRef] [PubMed]

17. Fergie, G.; Hunt, K.; Hilton, S. What young people want from health-related online resources: A focus group study. J. Youth Stud. 2013, 16, 579-596. [CrossRef] [PubMed]

18. Ahmed, T.; Rizvi, S.J.R.; Rasheed, S.; Iqbal, M.; Bhuiya, A.; Standing, H.; Bloom, G.; Waldman, L. Digital Health and Inequalities in Access to Health Services in Bangladesh: Mixed Methods Study. JMIR mHealth uHealth 2020, 8, e16473. [CrossRef]

19. Halwas, N.; Griebel, L.; Huebner, J. eHealth literacy, Internet and eHealth service usage: A survey among cancer patients and their relatives. J. Cancer Res. Clin. Oncol. 2017, 143, 2291-2299. [CrossRef]

20. Halbach, S.M.; Enders, A.; Kowalski, C.; Pförtner, T.-K.; Pfaff, H.; Wesselmann, S.; Ernstmann, N. Health literacy and fear of cancer progression in elderly women newly diagnosed with breast cancer-A longitudinal analysis. Patient Educ. Couns. 2016, 99, 855-862. [CrossRef]

21. Brabers, A.E.M.; Rademakers, J.J.D.J.M.; Groenewegen, P.P.; Van Dijk, L.; De Jong, J.D. What role does health literacy play in patients' involvement in medical decision-making? PLoS ONE 2017, 12, e0173316. [CrossRef]

22. Lai, J.; Ma, S.; Wang, Y.; Cai, Z.; Hu, J.; Wei, N.; Wu, J.; Du, H.; Chen, T.; Li, R.; et al. Factors Associated with Mental Health Outcomes Among Health Care Workers Exposed to Coronavirus Disease 2019. JAMA Netw. Open 2020, 3, e203976. [CrossRef] [PubMed]

23. Schwartz, J.; King, C.-C.; Yen, M.-Y. Protecting Healthcare Workers During the Coronavirus Disease 2019 (COVID-19) Outbreak: Lessons from Taiwan's Severe Acute Respiratory Syndrome Response. Clin. Infect. Dis. 2020, 71, 858-860. [CrossRef] [PubMed]

24. Di Renzo, L.; Gualtieri, P.; Pivari, F.; Soldati, L.; Attinà, A.; Cinelli, G.; Cinelli, G.; Leggeri, C.; Caparello, G.; Barrea, L.; et al. Eating habits and lifestyle changes during COVID-19 lockdown: An Italian survey. J. Transl. Med. 2020, 18. [CrossRef] [PubMed]

25. Mitsutake, S.; Shibata, A.; Ishii, K.; Oka, K. Associations of eHealth Literacy with Health Behavior Among Adult Internet Users. J. Med. Internet Res. 2016, 18, e192. [CrossRef]

26. Bang, K.-S.; Kang, J.H.; Jun, M.H.; Kim, H.S.; Son, H.M.; Yu, S.J.; Kwon, M.K.; Kim, J.S. Professional values in Korean undergraduate nursing students. Nurse Educ. Today 2011, 31, 72-75. [CrossRef] 
27. Von Elm, E.; Altman, D.G.; Egger, M.; Pocock, S.J.; Gøtzsche, P.C.; Vandenbroucke, J.P. The Strengthening the Reporting of Observational Studies in Epidemiology (STROBE) statement: Guidelines for reporting observational studies. Bull. World Health Organ. 2007, 85, 867-872. [CrossRef]

28. Worldometer. 2021. Available online: https:/ / www.worldometers.info/world-population/ (accessed on 31 May 2021).

29. Bodas, M.; Peleg, K. Self-Isolation Compliance in The COVID-19 Era Influenced By Compensation: Findings From A Recent Survey In Israel. Health Aff. 2020, 39, 936-941. [CrossRef]

30. Bodas, M.; Siman-Tov, M.; Kreitler, S.; Peleg, K. Psychological Correlates of Civilian Preparedness for Conflicts. Disaster Med. Public Health Prep. 2017, 11, 451-459. [CrossRef]

31. Diviani, N.; Dima, A.L.; Schulz, P.J. A Psychometric Analysis of the Italian Version of the eHealth Literacy Scale Using Item Response and Classical Test Theory Methods. J. Med. Internet Res. 2017, 19, e114. [CrossRef]

32. Hayes, A. Integrating Mediation and Moderation Analysis: Fundamentals using PROCESS. In Introduction to Mediation, Moderation and Conditional Process Analysis; Guilford Publications: New York, NY, USA, 2013.

33. Choi, N.G.; DiNitto, D.M. The Digital Divide Among Low-Income Homebound Older Adults: Internet Use Patterns, eHealth Literacy, and Attitudes Toward Computer/Internet Use. J. Med. Internet Res. 2013, 15, e93. [CrossRef] [PubMed]

34. Kontos, E.; Blake, K.D.; Chou, W.-Y.S.; Prestin, A. Predictors of eHealth Usage: Insights on The Digital Divide from the Health Information National Trends Survey 2012. J. Med. Internet Res. 2014, 16, e172. [CrossRef]

35. Kim, E.-H.; Stolyar, A.; Lober, W.B.; Herbaugh, A.L.; Shinstrom, S.E.; Zierler, B.K.; Soh, C.B.; Kim, Y. Challenges to Using an Electronic Personal Health Record by a Low-Income Elderly Population. J. Med. Internet Res. 2009, 11, e44. [CrossRef]

36. Hale, T.M. Is there such a thing as an online health lifestyle? Examining the relationship between social status, Internet access, and health behaviors. Inf. Commun. Soc. 2013, 16, 501-518. [CrossRef]

37. Chaudhuri, M.S.; LE, M.T.; White, M.C.; Thompson, H.; Demiris, G. Examining health information, seeking behaviors of older adults. Comput. Inform. Nurs. 2013, 31, 547-553. [CrossRef]

38. Beck, F.; Richard, J.-B.; Nguyen-Thanh, V.; Montagni, I.; Parizot, I.; Renahy, E. Use of the Internet as a Health Information Resource Among French Young Adults: Results from a Nationally Representative Survey. J. Med. Internet Res. 2014, 16, e128. [CrossRef]

39. Prestin, A.; Vieux, S.N.; Chou, W.-Y.S. Is Online Health Activity Alive and Well or Flatlining? Findings from 10 Years of the Health Information National Trends Survey. J. Health Commun. 2015, 20, 790-798. [CrossRef]

40. Moreland, J.; French, T.L.; Cumming, G.P.; Bouamrane, M.-M.; Gilstad, H. The Prevalence of Online Health Information Seeking Among Patients in Scotland: A Cross-Sectional Exploratory Study. JMIR Res. Protoc. 2015, 4, e85. [CrossRef] 